\title{
Comparison of early and late surgery following colonic stenting for obstructive colorectal cancer
}

Hyunji Lee, Sung Uk Bae, Seong Kyu Baek, Woon Kyung Jeong

Department of Surgery, Keimyung University Donsan Medical Center, Daegu, Korea

Purpose: Colonic stenting as a bridge to surgery is an alternative to emergency surgery in patients with acute malignant colonic obstruction. This study aimed to compare the outcomes of early and late surgery after colonic stenting for obstructive colorectal cancer.

Methods: From March 2004 to August 2014, the medical records of obstructive colorectal cancer patients who underwent surgery after colonic stent insertion were retrospectively reviewed. The patients were divided into early surgery ( $\leq 7$ days after stenting) and late surgery ( $>7$ days after stenting) groups.

Results: Eighty-four patients underwent colonic stenting for obstructive colorectal cancer. Forty-six patients were ultimately enrolled: 18 in the early and 28 in the late surgery groups. The mean ages were 63.7 and 71.8 years, respectively $(P=0.01)$. Blood loss was lower in the early surgery group (median [interquartile range], 50 [50-50] mL vs. 50 [50-100] mL; $P=0.020$ ). The time to first flatus was longer in the early surgery group (3.0 [3.0-5.0] days vs. $2.0[2.0-3.0]$ days; $P=0.010)$. The time to first soft food intake was similar. Postoperative complications did not differ ( $16.7 \%$ vs. $14.3 \%$, respectively; $P=0.525)$ and no patients died.

Conclusion: Surgical outcomes were similar between early and late surgery. However, the former featured less blood loss, indicating less surgical difficulty. These results show that early surgery can be performed safely in obstructive colorectal cancer patients after colonic stenting if the patient's clinical condition is amenable to early surgery.

Keywords: Colorectal neoplasm, Endoscopic stenting, Intestinal obstruction

\section{INTRODUCTION}

An estimated 10\%-30\% of colorectal cancer patients suffer from colon obstruction, which can lead to pathological distention, bacterial infection, electrolyte imbalance, necrosis, and colon perforation [1]. Emergency surgery, an effective treatment option for acute malignant colonic obstruction, consists of tumor resection and stoma creation, followed by later stoma reversal. Emergency surgery, however, is associated with a high morbidity rate of up to $40 \%$ [2]. Additionally, stoma creation decreases patient quality of life.

Colonic stenting as a bridge to surgery is an alternative to emergency surgery in patients with acute malignant colonic obstruc-

Received: Sep 25, 2017 Accepted: Oct 23, 2017

Correspondence to: Woon Kyung Jeong

Department of Surgery, Keimyung University Dongsan Medical Center,

56 Dalseong-ro, Jung-gu, Daegu 41931, Korea

Tel: +82-53-250-7072, Fax: +82-53-250-7322

E-mail: wkjeong12@gmail.com

Copyright @ C Korean Society of Surgical Oncology

This is an Open Access article distributed under the terms of the Creative Commons Attribution Non-Commercial License (http://creativecommons.org/licenses/by-nc/4.0) which permits unrestricted non-commercial use, distribution, and reproduction in any medium, provided the original work is properly cited. tion. Colonic stenting alleviates acute obstruction, helps surgeons avoid emergency surgery, and enables preoperative bowel preparation for elective surgery. Therefore, it provides an opportunity for patients with obstructive colorectal cancer to undergo single-stage surgery with primary bowel anastomosis and avoid stoma-related complications and inconvenience [3]. Moreover, colonic stenting has shown no adverse effect on perioperative mortality, long-term survival, or progression of colorectal cancer [4].

Despite the widespread use of colonic stenting, the optimal interval between colonic stenting and surgery after achieving bowel decompression is controversial. Few studies have investigated the interval [5]. This study aimed to compare the outcomes of early versus late surgery after colonic stenting for obstructive colorectal cancer.

\section{METHODS}

\section{Study population and design}

From March 2004 to August 2014, the medical records of obstructive colorectal cancer patients who underwent surgery after colonic stent insertion at Keimyung University Dongsan Medical Center 
were retrospectively reviewed. The exclusion criteria were as follows: age $<20$ years, severe comorbidity as judged by an American Society of Anesthesiologists (ASA) score of 4, surgery with palliative intent, history of preoperative chemotherapy or radiotherapy, iatrogenic colonic perforation during colonic stenting, and failed colonic decompression after colonic stenting.

In the European guidelines, a 5- to 10-day interval between colonic stenting and elective surgery was suggested [5]. The suggested time interval was thought to be too broad for clinical implementation and required to become more explicit. Hence, we decided to compare the time intervals of within 7 days versus after 7 days. The patients were divided into two groups: surgery $\leq 7$ days after stenting (early surgery group) and surgery $>7$ days (late surgery group).

The two groups were compared in terms of patient demographics, clinical data, and perioperative outcomes. Postoperative morbidity and mortality were defined as an adverse event and death occurring within 30 days after colorectal surgery, respectively. Data on the following postoperative complications were collected and analyzed: surgical and non-surgical infections, urinary complications, and anastomotic leakage. Anastomosis leakage was defined as the symptoms and signs of peritonitis caused by anastomotic dehiscence, which was confirmed by abdominal computed tomography scan imaging.

\section{Colonic stenting and bowel preparation}

The colonic stents were inserted under fluoroscopy guidance by endoscopists with relevant experience and expertise. Successful colonic stenting was defined as complete stent coverage of colonic stenosis, passage of stool, and relief of the bowel obstruction as assessed by the resolution of clinical symptoms and radiological signs.

The patients who were judged as having successful colonic stenting received mechanical bowel preparation using polyethylene glycol starting 2 days before surgery.

\section{Statistical analyses}

Statistical analyses were performed with PASW Statistics ver. 18 software (SPSS Inc., Chicago, IL, USA). The data are displayed as frequencies and percentages for categorical variables and were analyzed with the Pearson's chi-square test or Fisher exact test. The Kolmogorov-Smirnov test was used to test the distribution of continuous variables. Normally distributed variables were subjected to examination with Student's t-test and the results are expressed as mean \pm standard deviation. Non-normally distributed continuous variables were examined with the Mann-Whitney $U$ test and the results are presented as median (interquartile range). The Kaplan-Meier method was used to analyze survival. Two-tailed val- ues of $\mathrm{P}<0.05$ were considered statistically significant.

\section{RESULTS}

\section{Demographics and clinical findings}

A total of 84 patients underwent colonic stenting for obstructive colorectal cancer. Patients who received colonic stenting for palliative purposes $(\mathrm{n}=22)$ or received preoperative chemoradiotherapy $(n=4)$ or chemotherapy $(n=12)$ after stent insertion were excluded. Forty-six patients were enrolled in this study. Of them, 18 were assigned to the early surgery group and 28 were assigned to the late surgery group (Fig. 1).

The mean interval from colonic stenting to surgery between the two groups was significantly different $(5.3 \pm 1.3$ days vs. $15.4 \pm 6.2$ days, respectively; $\mathrm{P}<0.010$ ). The interval ranges of two groups were 3 to 7 days and 8 to 33 days, respectively. The mean age of the early surgery group was younger than that of the late surgery group ( 63.7 years vs. 71.8 years; $\mathrm{P}=0.010$ ). There was no significant difference in sex ratio, body mass index, comorbidities, ASA score, tumor location, T stage, $\mathrm{N}$ stage, or American Joint Committee on Cancer stage (Table 1).

A total of 10 patients with stage IV colorectal cancer underwent surgery for primary colorectal cancer (six in the early group and four in the late group). Combined resection for metastatic lesions was performed simultaneously in three patients (two in the early group and one in the late group). One patient in the late surgery group underwent radiofrequency ablation for liver metastasis (Table 2).

\section{Perioperative results and complications}

Operations, surgical approach, stoma rate, and operation time did not differ significantly between the two groups (Table 3 ). No con-

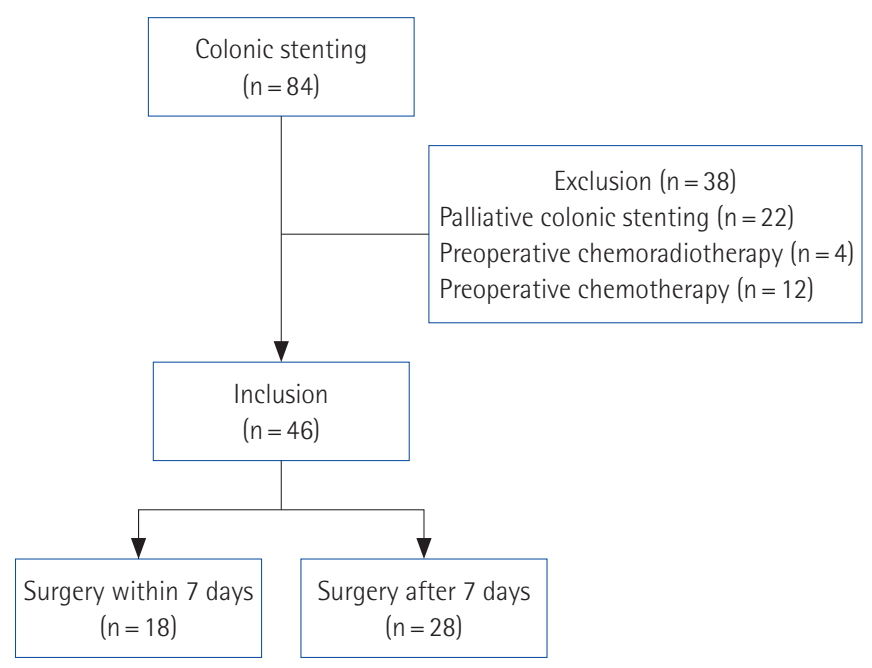

Fig. 1. Flowchart showing patient selection process in this study. 
Table 1. Demographics and clinical data

\begin{tabular}{|c|c|c|c|}
\hline Variable & $\begin{array}{c}\text { Early } \\
\text { surgery } \\
(n=18)\end{array}$ & $\begin{array}{c}\text { Late } \\
\text { surgery } \\
(n=28)\end{array}$ & P-value ${ }^{a)}$ \\
\hline From colonic stenting to surgery (day) & $5.3 \pm 1.3$ & $15.4 \pm 6.2$ & $<0.010^{b)}$ \\
\hline Age (yr) & $63.7(11.3)$ & $71.8(8.9)$ & $0.010^{b)}$ \\
\hline Sex (male:female) & $15: 3$ & $19: 9$ & 0.315 \\
\hline BMI $\left(\mathrm{kg} / \mathrm{m}^{2}\right)$ & $22.9 \pm 3.3$ & $23.3 \pm 3.1$ & $0.554^{b)}$ \\
\hline Comorbidity & & & 0.729 \\
\hline Hypertension & $6(33.3)$ & $5(17.9)$ & \\
\hline Diabetes & $1(5.6)$ & $5(17.9)$ & \\
\hline Cardiovascular disease & $4(22.2)$ & $6(21.4)$ & \\
\hline Pulmonary disease & $2(11.1)$ & $0(0)$ & \\
\hline ASA score & & & 0.403 \\
\hline I & $6(33.3)$ & $5(17.9)$ & \\
\hline ॥ & $10(55.6)$ & $17(60.7)$ & \\
\hline III & $2(11.1)$ & $6(21.4)$ & \\
\hline Tumor location & & & 0.051 \\
\hline Right colon & $3(16.7)$ & $0(0)$ & \\
\hline Left colon & $14(77.8)$ & $23(82.1)$ & \\
\hline Rectum & $1(5.6)$ & $5(17.9)$ & \\
\hline T stage & & & 0.131 \\
\hline 1 & $0(0)$ & $1(3.6)$ & \\
\hline 2 & $0(0)$ & $0(0)$ & \\
\hline 3 & 11 (61.1) & 23 (82.1) & \\
\hline 4 & 7 (38.9) & $4(14.3)$ & \\
\hline N stage & & & 0.863 \\
\hline 0 & $9(50.0)$ & $12(42.9)$ & \\
\hline 1 & $4(22.2)$ & 8 (28.6) & \\
\hline 2 & $5(27.8)$ & $8(28.6)$ & \\
\hline AJCC stage & & & 0.280 \\
\hline 2 & 7 (38.9) & $12(42.9)$ & \\
\hline 3 & $5(27.8)$ & $12(42.9)$ & \\
\hline 4 & 6 (33.3) & $4(14.3)$ & \\
\hline
\end{tabular}

Values are presented as mean \pm standard deviation or number (\%).

BMI, body mass index; ASA, American Society of Anesthesiologists; Right coIon, from the cecum to proximal transverse colon; Left colon, from the distal transverse colon to sigmoid colon; AJCC, American Joint Committee on Cancer. a) Pearson's $\chi^{2}$ test. ${ }^{b}$ Student's t-test. versions from laparoscopic to open surgery or from robotic to laparoscopic surgery occurred.

The postoperative course and complications are shown in Table 4. The degree of blood loss was lower in the early surgery group than in the late surgery group (median [interquartile range], 50 [50-50] mL vs. 50 [50-100] mL; $\mathrm{P}=0.020)$. The time to first flatus was longer in the early surgery group (3.0 [3.0-5.0] days vs. 2.0 [2.0-3.0] days; $\mathrm{P}=0.010)$. However, the time to first soft food intake (7.0 [5.0-8.0] days vs. $7.0[6.0-8.0]$ days; $\mathrm{P}=0.940)$ and length of stay (11.0 [9.75-12.0] days vs. 10.0 [9.5-14.5] days; $\mathrm{P}=0.632$ ) were similar. No significant difference was seen in postoperative complications $(16.7 \%$ vs. $14.3 \%$, respectively; $\mathrm{P}=0.525)$. Anastomosis leakage occurred in one patient in the early surgery group who underwent anterior resection and a right lobectomy for sigmoid colon cancer with liver metastasis 3 days after colonic stenting (patient 4 in Table 2). On postoperative day 7 , anastomosis leakage was diagnosed and managed with resection of the anastomosis and end colostomy. A total of three patients experienced a surgical site infection (SSI). One in each group had a superficial in-

Table 3. Perioperative outcomes between two groups

\begin{tabular}{lccc}
\hline Variable & $\begin{array}{c}\text { Early surgery } \\
(\mathrm{n}=18)\end{array}$ & $\begin{array}{c}\text { Late surgery } \\
(\mathrm{n}=28)\end{array}$ & P-value ${ }^{\text {a) }}$ \\
\hline $\begin{array}{l}\text { Operations } \\
\text { Left hemicolectomy }\end{array}$ & $4(22.2)$ & $4(14.3)$ & 0.111 \\
Anterior resection & $6(55.6)$ & $21(75.0)$ & \\
Hartmann's procedure & $1(5.6)$ & $3(10.7)$ & \\
Right hemicolectomy & $3(16.7)$ & $0(0)$ & \\
Surgical approach & & & \\
Open & $9(50.0)$ & $15(53.6)$ & \\
Laparoscopic & $7(38.9)$ & $13(46.4)$ & \\
Robotic & $2(11.1)$ & $0(0)$ & \\
Stoma creation & $3(16.7)$ & $6(21.4)$ & $>0.990$ \\
Operation time (min) & $180 \pm 54$ & $175 \pm 68$ & $0.826^{b)}$ \\
\hline
\end{tabular}

Values are presented as mean \pm standard deviation or number (\%).

a)Pearson's $\chi^{2}$ test. ${ }^{b}$ Student's t-test.

Table 2. Surgical resections in patients with stage IV colorectal cancer

\begin{tabular}{cccccc}
\hline Patient & Group & Primary cancer location & Metastasis location & Surgery for primary cancer & Combined resection for metastasis \\
\hline 1 & Early & Descending colon & Peritoneum & Left hemicolectomy & - \\
2 & Early & Sigmoid colon & Liver & Anterior resection & Right posterior sectionectomy (simultaneous) \\
3 & Early & Descending colon & Peritoneum & Left hemicolectomy & - \\
4 & Early & Sigmoid colon & Liver & Anterior resection & Right lobectomy (simultaneous) \\
5 & Early & Sigmoid colon & Liver (multiple) & Anterior resection & - \\
6 & Early & Rectum & Liver (multiple) & Low anterior resection & - \\
7 & Late & Sigmoid colon & Liver & Anterior resection & Left hepatectomy (simultaneous) \\
8 & Late & Rectum & Liver & Low anterior resection & Radiofrequency ablation (simultaneous) \\
9 & Late & Sigmoid colon & Liver (multiple) & Anterior resection & - \\
\hline 10 & Late & Descending colon & Peritoneum & Left hemicolectomy & - \\
\hline
\end{tabular}


Table 4. Postoperative course and complications

\begin{tabular}{lccc}
\hline Variable & $\begin{array}{c}\text { Early surgery } \\
(\mathrm{n}=18)\end{array}$ & $\begin{array}{c}\text { Late surgery } \\
(\mathrm{n}=\mathbf{2 8})\end{array}$ & P-value $^{\text {a) }}$ \\
\hline Loss of blood $(\mathrm{mL})$ & $50.0(50.0-50.0)$ & $50.0(50.0-100.0)$ & 0.020 \\
First flatus (day) & $3.0(3.0-5.0)$ & $2.0(2.0-3.0)$ & 0.010 \\
First soft food intake (day) & $7.0(5.0-8.0)$ & $7.0(6.0-8.0)$ & 0.940 \\
LOS (day) & $11.0(9.75-12.0)$ & $10.0(9.5-14.5)$ & 0.632 \\
Complication & $3(16.7)$ & $4(14.3)$ & 0.525 \\
Anastomotic leakage & $1(5.6)$ & $0(0)$ & \\
SSI & $1(5.6)$ & $2(7.1)$ & \\
UTI & $0(0)$ & $1(3.6)$ & \\
Pneumonia & $1(5.6)$ & $0(0)$ & \\
PMC & $0(0)$ & $1(3.6)$ & \\
Postoperative mortality & $0(0)$ & $0(0)$ & \\
\hline
\end{tabular}

Values are presented as median (IQR) or number (\%).

LOS, length of stay; SSI, surgical site infection; UTI, urinary tract infection;

PMC, pseudomembranous colitis; IQR, interquartile range.

a) Pearson's chi-square test.

Table 5. Recurrence sites of the two groups

\begin{tabular}{llll}
\hline Variable & $\begin{array}{c}\text { Early surgery } \\
(\mathrm{n}=18)\end{array}$ & $\begin{array}{c}\text { Late surgery } \\
(\mathrm{n}=\mathbf{2 8})\end{array}$ & P-value \\
\hline Recurrence & $3(16.7)$ & $9(32.1)$ & 0.315 \\
Local & 0 & 2 & \\
Systemic & 3 & 7 & \\
Liver & 2 & 3 & \\
Lung & 1 & 0 & \\
Peritoneum & 0 & 2 & \\
Multiple organs & 0 & 2 & \\
\hline
\end{tabular}

Values are presented as number (\%).

cisional SSI, while one patient in the late surgery group had organ/ space SSI and underwent percutaneous drainage. No case of mortality occurred in either group.

Cancer recurrence, disease-free survival, and overall survival During a median follow-up period of 30 months (range, 7-97 months), the disease recurrence rate was not different significantly between the two groups $(3 / 18,16.7 \%$ vs. $9 / 28,32.1 \% ; \mathrm{P}=0.315)$. Systemic recurrence occurred in three and seven patients in these groups, respectively. Two patients in late surgery group experienced local recurrence (Table 5).

The 5-year disease-free survival rate was similar in the early and late surgery groups ( $72.6 \%$ and $64.0 \%$, respectively; $\mathrm{P}=0.558$ ) (Fig. $2 \mathrm{~A})$. The 5 -year overall survival rate was lower in the late than early surgery group, but the difference was not significant (56.1\% vs. $60.8 \%$, respectively; $\mathrm{P}=0.437$ ) (Fig. $2 \mathrm{~B}$ ).
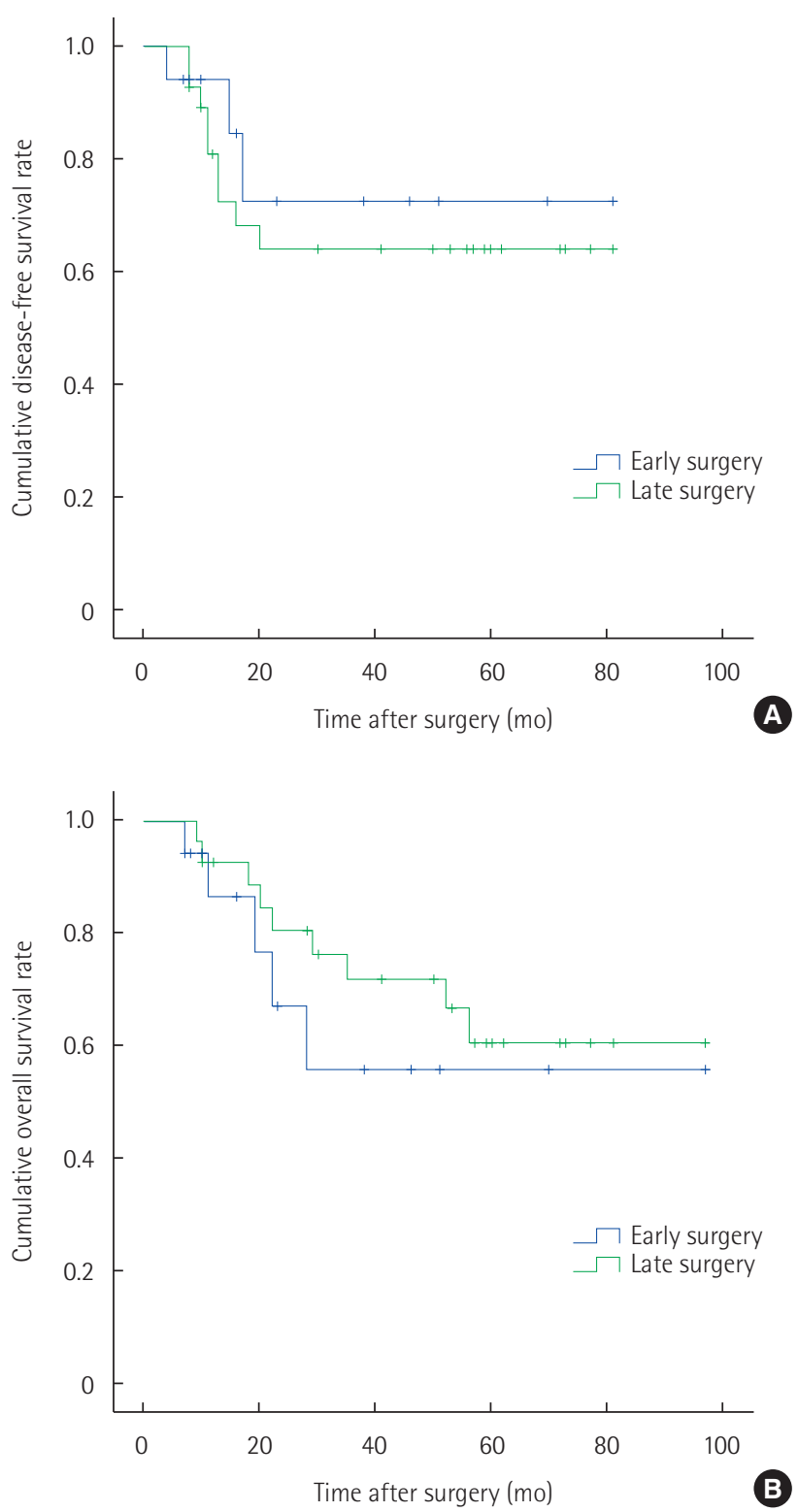

Fig. 2. (A) Disease-free and overall survival rates of the two groups. The 5 -year disease-free survival rate in the early surgery (72.6\%) and late surgery (64.0\%) groups ( $\mathrm{P}=0.558)$. (B) The 5 -year overall survival rates were $56.1 \%$ vs. $60.8 \%$, respectively $(P=0.437)$.

\section{DISCUSSION}

The optimal timing of surgery after colonic stenting has not been established. In the European guidelines, the suggested time interval between colonic stenting and surgery is $5-10$ days when colonic stenting is used as a bridge to elective surgery in patients with potentially curable left-sided colon cancer [5]. The time interval in the guideline was determined based on a few studies with different qualities. For this reason, the recommendation on the time interval is weak and the level of evidence is low. In a meta-analysis compar- 
ing colonic stenting as bridge to surgery and emergency surgery for left-sided colorectal cancer obstruction, surgery was generally performed after a median 10 days after colonic stenting [6]. This study, however, did not aim to determine the optimal time interval between colonic stenting and surgery. Moreover, the median 10 days resulted from statistical analysis of the data from the included studies. A retrospective study concluded that a duration of 7-9 days after colonic stenting in patients with obstructive left-sided colon cancer is sufficient to subsequently perform a safe surgical procedure. This study, however, has limitations for drawing the conclusion. It was a single arm study that did not compare the patient groups according to the time interval after colonic stenting whose conclusion was supported by limited and logically flawed descriptions [7]. Thus, well-designed, highly reliable studies are required to conclude the optimal timing of surgery after colonic stenting.

In this study, the patients in the early surgery group were younger than those in the late surgery group. It is a common belief that the general health and performance status of young patients are better than those of older ones. Older patients usually require more preoperative examinations. Nonetheless, age does not usually influence the timing of surgery after colonic stenting. In our previously published study comparing the postoperative outcomes of obstructive colorectal cancer patients aged $<70$ years and those aged $\geq 70$ years, the time interval between colonic stenting and surgery did not differ significantly between the two groups and the postoperative complications were similar [8]. According to the results of the previous study, the difference in age between the early and late surgery groups is not thought to affect the comparison of the postoperative outcomes. In addition, comorbidities, ASA score, and other variables influencing on the preoperative checkup and postoperative complications, did not differ between the two groups in the present study.

The operation time and blood loss are variables representative of surgical difficulty [9]. In this study, the operation time did not differ significantly between the two groups. Estimated blood loss was lower in the early surgery group, which indicates a lower degree of surgical difficulty. These results show that early surgery can be performed without increased surgical difficulty.

The postoperative course of the two groups was similar in this study. Despite the early surgery group having a longer time to first flatus, no significant differences were found in the time to first soft food intake or, eventually, length of stay.

The postoperative complication rate is similar between two groups ( $16.7 \%$ vs. $14.3 \%$, respectively; $\mathrm{P}=0.525)$. The complication rate $(7 / 46,15.2 \%)$ was consistent with those of other studies of $8.5 \%-25 \%[8,10,11]$.
Anastomosis leakage of the most concerning complications of surgery following colonic stenting. Incomplete resolution of bowel wall edema is thought to contribute to the occurrence of anastomosis leakage. The time interval after colonic stenting to achieve an appropriate bowel thickness for safe anastomosis, although not well known, is influenced by many factors such as stent expansion, obstructive bowel length, obstruction duration, and nutritional status. In the present study, one patient who underwent anterior resection 3 days after colonic stenting with a simultaneous right lobectomy for liver metastasis developed anastomosis leakage on postoperative day 7 . Thus, 3 days might be an insufficient time for the normal physiology of the bowel to resume. Additionally, a wide range of surgical interventions would be another risk factor for anastomosis leakage. Except for that one patient, no other patients in the early surgery group developed anastomosis leakage regardless of stoma status. In the present study, achieving a suitable bowel status for a safe anastomosis was possible within 7 days. The rates of anastomosis leakage in all patients and those without a stoma were $2.2 \%(1 / 46)$ and $2.7 \%(1 / 37)$, respectively. These rates are consistent with those of other studies (range, 0\%-10.6\%) [6-8].

In this study, the surgical timing did not affect oncologic outcomes. No significant differences were noted in 5-year disease-free and overall survival rates. In the literature, few studies have analyzed the effect of surgical timing after colonic stenting on oncologic outcomes. Oncologic outcomes between elective surgery following colonic stenting and emergency surgery are controversial. Some studies reported comparable oncologic outcomes of elective surgery after colonic stenting to emergency surgery [12-14]. In contrast to our findings, worse oncologic outcomes of colonic stenting were published $[15,16]$. These outcomes are mainly associated with tumor cell dissemination caused by tumor perforation related to colonic stenting and stent placement [16-18]. A longer interval between colonic stenting and surgery may increase the risk of stent-related complications including tumor perforation [5]. In the present study, no tumor perforation or other stent-related complications occurred in enrolled patients regardless of the surgical timing, which might be a reason for the lack of oncologic differences between the two groups.

There are limitations of the present study. First, it was not a prospective controlled study, so it carries the risk of selection bias. Second, its relatively small number of enrolled patients may reduce the power of its results.

In conclusion, outcomes were similar between early and late surgery patients. However, early surgery patients had less blood loss, which indicates a lower degree of surgical difficulty. These results show that early surgery can be performed safely to treat obstructive colorectal cancer patients after colonic stenting if the pa- 
tient's clinical condition is amenable to early surgery.

\section{CONFLICT OF INTEREST}

No potential conflict of interest relevant to this article was reported.

\section{REFERENCES}

1. Tan CJ, Dasari BV, Gardiner K. Systematic review and meta-analysis of randomized clinical trials of self-expanding metallic stents as a bridge to surgery versus emergency surgery for malignant left-sided large bowel obstruction. Br J Surg 2012;99:469-76.

2. Iversen LH, Bulow S, Christensen IJ, Laurberg S, Harling H, Danish Colorectal Cancer Group. Postoperative medical complications are the main cause of early death after emergency surgery for colonic cancer. Br J Surg 2008;95:1012-9.

3. Dulucq JL, Wintringer P, Beyssac R, Barberis C, Talbi P, Mahajna A. One-stage laparoscopic colorectal resection after placement of self-expanding metallic stents for colorectal obstruction: a prospective study. Dig Dis Sci 2006;51:2365-71.

4. Zhang Y, Shi J, Shi B, Song CY, Xie WF, Chen YX. Self-expanding metallic stent as a bridge to surgery versus emergency surgery for obstructive colorectal cancer: a meta-analysis. Surg Endosc 2012; 26:110-9.

5. van Hooft JE, van Halsema EE, Vanbiervliet G, Beets-Tan RG, DeWitt JM, Donnellan F, et al. Self-expandable metal stents for obstructing colonic and extracolonic cancer: European Society of Gastrointestinal Endoscopy (ESGE) Clinical Guideline. Gastrointest Endosc 2014;80:747-61.e1-75.

6. De Ceglie A, Filiberti R, Baron TH, Ceppi M, Conio M. A meta-analysis of endoscopic stenting as bridge to surgery versus emergency surgery for left-sided colorectal cancer obstruction. Crit Rev Oncol Hematol 2013;88:387-403.

7. Abdussamet Bozkurt M, Gonenc M, Kapan S, Kocatass A, Temizgonul B, Alis $\mathrm{H}$. Colonic stent as bridge to surgery in patients with obstructive left-sided colon cancer. JSLS 2014;18:e2014. 00161.

8. Park CH, Baek SK, Bae OS, Jeong WK. Influence of old age on the postoperative outcomes of obstructive colorectal cancer surgery after the insertion of a stent. Ann Surg Treat Res 2015;89:183-9.

9. Veenhof AA, Engel AF, van der Peet DL, Sietses C, Meijerink WJ, de Lange-de Klerk ES, et al. Technical difficulty grade score for the laparoscopic approach of rectal cancer: a single institution pilot study. Int J Colorectal Dis 2008;23:469-75.

10. Kim JS, Hur H, Min BS, Sohn SK, Cho CH, Kim NK. Oncologic outcomes of self-expanding metallic stent insertion as a bridge to surgery in the management of left-sided colon cancer obstruction: comparison with nonobstructing elective surgery. World J Surg 2009;33:1281-6.

11. Jimenez-Perez J, Casellas J, Garcia-Cano J, Vandervoort J, Garcia-Escribano OR, Barcenilla J, et al. Colonic stenting as a bridge to surgery in malignant large-bowel obstruction: a report from two large multinational registries. Am J Gastroenterol 2011;106:217480.

12. Kim HJ, Choi GS, Park JS, Park SY, Jun SH. Higher rate of perineural invasion in stent-laparoscopic approach in comparison to emergent open resection for obstructing left-sided colon cancer. Int J Colorectal Dis 2013;28:407-14.

13. Kavanagh DO, Nolan B, Judge C, Hyland JM, Mulcahy HE, O'Connell PR, et al. A comparative study of short- and medium-term outcomes comparing emergent surgery and stenting as a bridge to surgery in patients with acute malignant colonic obstruction. Dis Colon Rectum 2013;56:433-40.

14. Kim HJ, Huh JW, Kang WS, Kim CH, Lim SW, Joo YE, et al. Oncologic safety of stent as bridge to surgery compared to emergency radical surgery for left-sided colorectal cancer obstruction. Surg Endosc 2013;27:3121-8.

15. Gorissen KJ, Tuynman JB, Fryer E, Wang L, Uberoi R, Jones OM, et al. Local recurrence after stenting for obstructing left-sided colonic cancer. Br J Surg 2013;100:1805-9.

16. Sloothaak DA, van den Berg MW, Dijkgraaf MG, Fockens P, Tanis PJ, van Hooft JE, et al. Oncological outcome of malignant colonic obstruction in the Dutch Stent-In 2 trial. Br J Surg 2014;101:17517.

17. Maruthachalam K, Lash GE, Shenton BK, Horgan AF. Tumour cell dissemination following endoscopic stent insertion. Br J Surg 2007;94:1151-4.

18. Suarez J, Jimenez-Perez J. Long-term outcomes after stenting as a "bridge to surgery" for the management of acute obstruction secondary to colorectal cancer. World J Gastrointest Oncol 2016;8: 105-12. 